\title{
FUNDO GARANTIDOR PARA A AGRICULTURA FAMILIAR: UM MECANISMO PARA A ALAVANCAGEM DE RECURSOS
}

\author{
Paulo Augusto Pettenuzzo de Britto* \\ Carlos Henrique Marques Rocha**
}

\begin{abstract}
RESUMO: A agricultura familiar tem pouco acesso ao crédito para custeio e a seguro contra riscos de sua atividade. Dada a importância adquirida pela agricultura familiar nas últimas décadas, os governos têm implementado programas oficiais de apoio. Tais programas são prioritariamente financiados com recursos orçamentários. Com o objetivo de reduzir a dependência de recursos orçamentários e facilitar o acesso dos agricultores familiares ao mercado financeiro, este artigo sugere a criação de um fundo fiduciário garantidor, composto por ativos integralizados pela União e por contribuições dos próprios agricultores. O fundo garantidor serviria ao propósito de assegurar o serviço de dívidas de agricultores em caso de perdas de produção, sinistros. Nos períodos de resultados positivos, os agricultores fariam aportes de recursos ao fundo de forma a garantir um resultado atuarial superior.
\end{abstract}

PALAVRAS-CHAVE: Agricultura Familiar; Fundo Fiduciário Garantidor de Crédito; Seguro.

\section{A GUARANTEE RESOURCE IN FAMILY AGRICULTURE: MECHANISM FOR SUSTAINING RESOURCES}

ABSTRACT: Family agriculture has practically neither credit access nor insurance against risks. Several administrations have implemented supporting programs due to the importance of family agriculture. Programs are financed as a priority through the budget. Current analysis suggests the establishment of a guarantee credit composed of resources derived from the State and from contributions by farmers to reduce dependence of budget resources and make easy access to financial market by family agriculture farmers. The guarantee fund would guarantee interests of farmers' debts when there are losses in production and other liabilities. During positive periods, the farmers provide resources to the fund to guarantee high actuarial results.

KEY WORDS: Family agriculture; Credit guarantee; Insurance.

\footnotetext{
"PhD em Economia, University of Illinois. Docente de Economia e Finanças Programa de Pós-Graduação em Contabilidade Faculdade de Economia, Administração e Contabilidade, Universidade de Brasília, Brasil. E-mail: pbritto@unb.br

${ }^{* *} \mathrm{PhD}$ em Economia pela Universidade de Liverpool. Professor Associado III na Universidade de Brasília. Departamento de Ciências Contábeis e Atuarias. Pesquisador CNPq de Produtividade. Brasil.
} 


\section{INTRODUÇÃO}

A atividade agrícola é vulnerável às adversidades climáticas, tais como seca, granizo, tromba d'água, vendaval e chuva, e biológicas (BUAINAIN; SOUZA FILHO, 2001). Para atenuar os efeitos negativos de infortúnios climáticos e biológicos sobre a renda dos produtores e, consequentemente, garantir produção em níveis eficientes, sugere-se, entre outras medidas, o uso de seguro, que é um instrumento apropriado para a transferência de riqueza de épocas boas para épocas ruins e, portanto, para a estabilização da renda dos produtores rurais (MENDES; PADILHA JUNIOR, 2007).

O seguro agrícola, assim como todo seguro, está sujeito aos riscos inerentes à atividade segurada e ao comportamento específico dos agentes contratantes (SEEKS, 1999). Tanto os agentes financeiros ofertantes do seguro como os agentes contratantes devem estimar probabilidades de ocorrência de sinistros associados aos riscos e avaliar como essas probabilidades são afetadas pelo compartamento do contratante. $\mathrm{O}$ contrato de seguro somente será transacionado se ambos os agentes obtiverem ganhos esperados não-negativos. A estimação dos riscos depende de informações privadas, o que pode gerar assimetria de informação entre agentes financeiros e contratantes e, portanto, promover expectativas distintas acerca do resultado futuro do contrato. A assimetria de informação acaba por gerar dois problemas bem conhecidos e que estão sempre presentes em mercados de seguro: a selecão adversa e o risco moral.

É sabido que o interesse das instituições financeiras privadas em prover financiamentos e seguros para a produção agrícola é pequeno devido ao caráter multirisco dessa atividade (CHAMBERS, 1989; QUIGGIN et al., 1993). Mesmo em mercados onde existe oferta de seguro agrícola, a agricultura familiar tem pouco acesso a esse serviço financeiro devido ao problema do risco moral ser agravado pela presença de restrições técnicas e orçametárias mais severas relativas à implantação de ações que reduzem o risco de perdas associadas a fatores climáticos e a doenças (GARDNER, 1994; OZAKI; SHIROTA, 2006). Além disso, conforme argumentam Guse et al. (2015), as empresas agrícolas familiares são vistas como menos eficientes, pelo menos no curto-prazo, comparativamente às empresas não familiares.

Se, por um lado, a agricultura familiar tem limitado acesso ao crédito e 
ao seguro, por outro, possui grande importância para o desenvolvimento do país, conforme observam Guanziroli (2007), Guilhoto et al. (2006) e Serenini e Malysz (2015). Seguno Sangalli et al. (2015), a agricultura familiar responde por mais de $80 \%$ da ocupação no setor rural brasileiro, emprega sete de cada dez trabalhadores no campo e produz cerca de $40 \%$ da produção agrícola nacional. Esses autores acrescentam ainda que a maior parte dos alimentos que abastecem a mesa da população brasileira, nos dias de hoje, provém dos pequenos lotes de produção agrícola.

Em função da importância da agricultura familiar para a economia e para o desenvolvimento nacional, esse setor produtivo é objeto de diversas ações governamentais, tendo como marco institucional a criação do Programa Nacional de Fortalecimento da Agricultura Familiar (PRONAF), em 1995, e, mais recenemente, de novas políticas e incentivos com o objetivo de elevar o dinamismo do setor entre essas políticas cabe citar, em particular, o Programa Rede Brasil Rural (CARVALHO et al., 2015).

O PRONAF é o principal programa de crédito para a agricultura familiar no Brasil. Está presente em 98\% dos municípcios nacionais e disponibilizou para o ano safra 2014/2015 mais de R\$ 24 bilhões. Contudo, o PRONAF é sustentado exclusivamente por recursos oriundos do Tesouro Nacional, estando sujeito, portanto, às decisões políticas e às restrições orçamentárias. No âmbito do PRONAF, um mecanismo importante é o Seguro da Agricultura Familiar, o SEAF, instituído com o objetivo de garantir a cobertura do financiamento contraído junto ao PRONAF para custeio agrícola e da receita líquida esperada pelo empreendimento financiado.

Nesse contexto, este artigo propõe um mecanismo específico capaz de elevar a disponibilidade de recursos privados para o financiamento de pequenos empreendimentos agropecuários, de reduzir a dependência de fontes orçamentárias da União e de aprimorar o desempenho atuarial do SEAF.

$\mathrm{O}$ artigo tem quatro seções, incluindo esta introdutória. A seção dois apresenta uma breve fundamentação teórica acerca de seguros e garantias. A seção três descreve o Seguro da Agricultura Familiar (SEAF) no âmbito do PRONAF. A seção quatro estrutura o fundo garantidor do SEAF tendo como embasamento teórico a teoria dos mercados monetários e de capitais. A seção cinco encerra o artigo. 


\section{SEGURO E GARANTIAS: FUNDAMENTAÇÃO TEÓRICA}

Em um contrato de seguro, o objeto transacionado entre as empresas seguradoras e os segurados é a minimização de riscos (MACHADO; PAULO, 2006). Assim, mediante uma quantia, chamada de prêmio, o segurado transfere parte de sua riqueza presente para a seguradora, que, em troca, garante-lhe o recebimento de certo valor, caso ocorra evento futuro e incerto (i.e. sinistro) que possa diminuir seu patrimônio.

Para determinar o prêmio, a seguradora precisa conhecer a probabilidade de ocorrência do sinistro que gera a indenização (SILVA, 1999). O valor mínimo a ser cobrado deve ser igual aos custos administrativos somados à indenização multiplicada pela probabilidade de que ela tenha de ser paga. Formalmente, o cálculo é simples: sendo $p$ a probabilidade de ocorrência do sinistro, $y$ o valor da indenização, $x$ o valor do prêmio e $c$ os custos operacionais. Então, somente serão ofertados no mercado contratos de seguro tais que $x \geq p y+c$.

Considerando-se, ainda, a viabilidade do negócio, a seguradora precisa diversificar os riscos que assume. Para tanto, a sua base de clientes tem de ser grande, de modo que a ocorrência do sinistro em um contrato não esteja correlacionada com a ocorrência de sinistros em outros contratos (MACHADO; PAULO, 2006). Dessa maneira, minimiza-se o risco de que, em um determinado período, a empresa tenha de pagar muitas indenizações.

Do ponto de vista do segurado, o objeto adquirido é a segurança de que, havendo sinistro, ao menos parte de sua riqueza seja restituída pela seguradora. A determinação de aquisição de um seguro e de quanto pagar por ele depende, além do comportamento do segurado diante do risco, da probabilidade que ele atribui à eventual ocorrência do sinistro e do tamanho do prejuízo esperado. Dadas suas preferências, quanto maior a probabilidade de ocorrência do evento indesejado, mais propenso está o consumidor a gastar parte de seu patrimônio presente com a finalidade de minimizar possível perda. Do mesmo modo, quanto maior for o prejuízo esperado pelo consumidor em caso de sinistro, mais propenso estará em fazer o seguro. Além disso, sob a ótica do segurado, seu grau de aversão ao risco importa para a decisão de aquisição ou não do seguro - agentes mais avessos ao risco 
tendem a contratar mais seguro, demonstrando maior disposição de pagamento.

Tendo em vista os dois lados da transação, o preço do seguro relaciona-se, principalmente, à probabilidade associada ao evento que gera uma indenização de valor determinado. Como maior risco e maior indenização implicam em um valor mais elevado do prêmio do seguro e vice-versa, tanto seguradora como segurados têm incentivos conflitantes ao estimar esses valores.

Quanto mais eficientemente uma seguradora conseguir calcular essa probabilidade, mais consumidores atrairá na medida em que poderá oferecer um contrato bastante ajustado às necessidades de cada provável segurado. Aos potenciais segurados de baixo risco, a seguradora oferecerá um contrato com prêmio menor e maior cobertura; aos consumidores de alto risco, a seguradora oferecerá um contrato com prêmio maior e menor cobertura (AZEVEDO, 2010).

A capacidade da seguradora em ofertar contratos de seguro ajustados a cada consumidor é limitada, principalmente por restrições em sua capacidade de obter informações sobre os riscos associados ao sinistro. A assimetria de informação entre seguradora e consumidor, em mercados de seguro, é bem documentada na literatura de Teoria da Agência, com a discussão de dois problemas especificos: a seleção adversa e o risco moral.

A Teoria da Agência trata de relações entre entes econômicos sob assimetira de informação (MILGROM; ROBERTS, 1992). Em especial, em uma proposição bem simples, a Teoria lida com a relação entre um ente, o principal, que contrata outro, o agente, para atuar em seu nome. Sob assimetria de informação e dificuldades de monitoramento, a contratação deve ser regida por um contrato que especifique ações que o agente deve tomar em diferentes circunstâncias, sempre visando à maximização da riqueza do principal. $O$ agente, prevê a Teoria, deve receber uma remuneração de incentivo, algum tipo de gratificação associada ao ganho do principal. No caso de um seguro, a relação entre seguradora e segurado pode ser analisada sob a Teoria da Agência na medida em que essa teoria reconhece a dificuldade da seguradora em avaliar com precisão o tipo do segurado, antes da contratação, e em monitorar seu comportamento, após a contratação. Com efeito, o segurado tem incentivo para reportar um tipo menos arriscado antes, e para assumir riscos maiores depois da contratação. 
Vale destacar que a aplicação da Teoria da Agência ao mercado de seguros não é só aceita teoricamente, mas também comprovada empiricamente. Quiggin et al. (1993), por exemplo, avaliaram com dados do tipo cross-section a presença de seleção adversa e de risco moral no setor de seguro agrícola. Os seus resultados mostraram que a viabilidade da seguradora é prejudicada pela manifestação de informação assimétrica no setor agrícola.

Segundo Baye (2010), a seleção adversa consiste do oferecimento de contratos de seguro a preços médios para agentes distintos, o que induz apenas os agentes de alto risco a contratar o seguro. Em outras palavras, a seleção adversa refere-se a uma situação em que indivíduos têm características ocultas, na qual um processo de seleção como o realizado na contratação de um seguro resulta em um conjunto de pessoas com características indesejadas. O risco moral, por seu turno, de acordo com Baye (2010), consiste de mudanças no comporamento do contratante após a efetivaçao do seguro, com o objetivo de poupar custos, o que, consequentemente, induz a maior risco. Ou seja, o risco moral refere-se a uma situação na qual um segurado toma uma ação oculta que o beneficia à custa da contratada. Enfim, esses dois problemas tendem a restringir o desenvolvimento do mercado de seguros.

Um possível mitigador dos problemas de seleção adversa e de risco moral associados ao seguro é a garantia. Uma garantia consubstancia um contrato entre um devedor e um garantidor, ao se estabelecer que o garantidor se obriga a satisfazer uma obrigação junto a um credor, caso o devedor não a cumpra. Esse entendimento legal é consagrado na literatura acadêmica em que uma garantia representa os ativos oferecidos como cobertura do pagamento da dívida (ROSS et al., 2007).

Segundo Azúa (2002), a principal diferença entre garantia e seguro reside no fato de que, no caso da garantia, o ônus associado ao risco somente existe quando o risco efetivamente acontece. No caso do seguro, contudo, o ônus existe na forma do pagamento de um preço em contraprestação a assinatura do contrato, independentemente da ocorrência do sinistro. Na prática, ainda conforme Azúa (2002), dificilmente uma garantia é coberta sem ônus, seja na forma de um período decorrido entre sua emissão e seu uso efetivo, seja na forma de uma contraprestação pecuniária exigida no contrato. Nesses casos, garantias e seguros se assemelham. 
Um fundo fiduciário constitui uma tentativa de mitigação de risco de financiamento privado através de constituição de um fundo cujo patrimônio serve como garantia do pagamento de contrapartidas financeiras em caso de dificuldade de fluxos de caixa de um empreendimento (BODIE; KANE; MARCUS, 2010). Em tais fundos, a garantia se configura como um direito real de alienação do conjunto dos ativos transferidos ao fundo. A constituição de um fundo fiduciário permite melhoria do crédito, o credit enhancement, por meios de garantias distintas e dissociadas dos ativos dos empreendedores.

Um tipo particular de fundo garantidor é o investment trust fund, geralmente empregado em situações em que governos patrocinam investimentos realizados por entes privados, em geral consórcios, em nome do próprio governo. Esse tipo de fundo é bastante empregado na engenharia financeira de grandes projetos de infraestrutura (BOQUI, 2008) em que, na condição de patrocinador, o governo aporta ativos próprios de forma a integralizar as garantias necessárias.

\section{O SEGURO DA AGRICULTURA FAMILIAR (SEAF)}

O Programa Nacional de Fortalecimento da Agricultura Familiar (PRONAF) consiste de um programa de crédito oficial do governo federal brasileiro instituído com o objetivo de financiar projetos com capacidade para geração de renda aos agricultores familiares e assentados da reforma agrária com renda bruta anual de até R\$ 110 mil. Freitas et al. (2012) observam que o PRONAF é a principal expressão do paradigma do crescimento agrícola baseado na eficiência da pequena produção no Brasil, marcando a inclusão no processo de desenvolvimento do país de políticas orientadas aos grupos organizados, e sindicalizados, de trabalhadores rurais.

Segundo dados do Ministério do Desenvolvimento Agrário, desde 2000 foram disponibilizados ao PRONAF R $\$ 72,34$ bilhões de recursos oriundos do Tesouro Nacional; os empréstimos concedidos no período representaram $75 \%$ desse montante. No âmbito do PRONAF, o Governo brasileiro instituiu, em 2004, o Seguro da Agricultura Familiar (SEAF), instituído exclusivamente para segurar os agricultores familiares que contratam financiamentos de custeio agrícola no PRONAF.

O SEAF tem como objetivo garantir a cobertura de $100 \%$ do financiamento 
contraído junto ao PRONAF, para custeio agrícola, e mais 65\% da receita líquida esperada pelo empreendimento financiado pelo agricultor familiar. Os agentes financeiros que atuam no PRONAF compõem o segmento varejista do seguro, com vendas diretas para os agricultores. $\mathrm{O}$ valor segurado é igual ao valor financiado mais parcela de $65 \%$ da receita líquida esperada, limitada a $\mathrm{R} \$ 3.500$ por ano por agricultor. O valor do prêmio do SEAF está estipulado em $2 \%$, valor equivalente a $\mathrm{R} \$ 70$ por ano, no caso de contrato estipulado no limite financeiro imposto pelo programa.

Ainda com relação ao SEAF, dados o prêmio e o número de períodos de capitalização, pode-se calcular a taxa de retorno da operação-SEAF, do ponto de vista do agricultor segurado, em significativos $4.900 \%$ ao ano. Dada essa taxa, não é arriscado afirmar que o SEAF incentiva o problema do risco moral.

Para as safras dos períodos de 2006/2007 até 2013/2014, conforme dados do Banco Central do Brasil, apresentados na Tabela 1, foram contratados mais de 4 milhões de seguros em montante de aproximandamente $\mathrm{R} \$ 41$ bilhões.

Tabela 1. Informações Financeiras do Seguro da Agricultura Familiar*, 2006-2014

\begin{tabular}{|c|c|c|c|c|c|c|c|}
\hline \multirow{3}{*}{$\begin{array}{l}\text { Ano } \\
\text { Agrícola }\end{array}$} & \multicolumn{3}{|c|}{ Contratação de Seguro } & \multicolumn{3}{|c|}{ Pagamentos por Sinistros } & \multirow{3}{*}{$\begin{array}{l}{[\mathrm{B}] /[\mathrm{A}]} \\
(\mathrm{em} \%)\end{array}$} \\
\hline & \multirow[t]{2}{*}{$\begin{array}{l}\text { Quanti- } \\
\text { dade de } \\
\text { Adesões }\end{array}$} & \multicolumn{2}{|c|}{$\begin{array}{l}\text { Valor Enquadrado } \\
\qquad(\mathrm{R} \$ \mathrm{mil})\end{array}$} & \multirow{2}{*}{$\begin{array}{l}\mathrm{N}^{\mathrm{o}} \mathrm{de} \\
\text { Comuni- } \\
\text { cações }\end{array}$} & \multicolumn{2}{|c|}{$\begin{array}{l}\text { Valor Enquadrado } \\
\qquad(\mathrm{R} \$ \text { mil })\end{array}$} & \\
\hline & & Total [A] & Médio & & Total [B] & Médio & \\
\hline $2006 / 07$ & 630.818 & 2.869 .210 & 4.705 & 29.272 & 69.542 & 2.376 & 2,34 \\
\hline $2007 / 08$ & 590.743 & 3.717 .886 & 6.294 & 38.739 & 133.344 & 3.442 & 3,59 \\
\hline $2008 / 09$ & 531.861 & 4.850 .281 & 9.119 & 70.956 & 379.436 & 5.347 & 7,82 \\
\hline $2009 / 10$ & 501.889 & 4.641 .995 & 9.249 & 8.398 & 43.447 & 5.173 & 0,94 \\
\hline $2010 / 11$ & 455.117 & 5.093 .200 & 11.191 & 12.980 & 101.383 & 7.811 & 1,99 \\
\hline $2011 / 12$ & 454.982 & 5.502 .281 & 12.093 & 101.498 & 766.317 & 7.550 & 13,93 \\
\hline $2012 / 13$ & 444.195 & 6.990 .508 & 15.737 & 22.658 & 256.623 & 11.326 & 3,67 \\
\hline $2013 / 14$ & 428.452 & 7.697 .453 & 17.966 & 33.195 & 434.427 & 13.087 & 5,64 \\
\hline \multicolumn{8}{|c|}{$\begin{array}{l}\text { Fonte: BCB }(2012 ; 2014) \text {. } \\
\text { * Dados do Proagro Mais - seguro público destinado aos pequenos produtores vinculados ao PRC } \\
\text { NAF. }\end{array}$} \\
\hline
\end{tabular}


A quantidade de empreendimentos com a contratação do Programa de Garantia da Atividade Agropecuária (Proagro) apresentou tendência declinante ao longo do período. Por outro lado, o valor enquadrado médio se elevou no mesmo período, passando de $\mathrm{R} \$ 4,7$ mil no ano agrícola 2006/2007 para $\mathrm{R} \$ 17,96 \mathrm{mil} \mathrm{em}$ 2013/2014. Como consequência, o valor enquadrado total se elevou de $\mathrm{R} \$ 2,8$ bilhões no ano agrícola 2006/2007 para $\mathrm{R} \$ 7,6$ bilhões em 2013/2014, um crescimento médio anual de 15\%. Segundo o Relatório do Proagro do Banco Central do Brasil, esse aumento foi resultado, principalmente, da elevação dos preços dos insumos e do crescimento da área média plantada por produtor.

Com respeito às comunicações de perdas, verifica-se o pagamento por sinistros da ordem de $\mathrm{R} \$ 2,18$ bilhões, montante equivalente a 5,3\% do valor enquadrado. Considerando-se o prêmio de $2 \%$, foram arrecadados $\mathrm{R} \$ 824$ milhões no período 2006 a 2014, implicando em desequilíbrios entre o valor arrecadado e o valor pago. De fato, o SEAF registrou superávit apenas no ano safra 2009/2010, tendo sido atuarialmente justo apenas no ano safra 2010/2011.

Observa-se que a ocorrência de sinistros na agricultura familiar no âmbito do SEAF penaliza a sociedade duplamente. Primeiro porque se deve pagar o seguro e, depois, porque os preços dos produtos agrícolas tendem a aumentar. Nesse sentido, percebe-se que programas oficiais de garantia de renda à agricultura familiar envolvem um trade-off: Se, por um lado, consistem em um instrumento de proteção da renda agrícola familiar, por outro, tendem a onerar o erário. Com efeito, não obstante o mérito do apoio à agricultura familiar, conforme discutido em Freitas et al. (2012), materializado nos programas específicos de apoio, não seria nada ruim se as perdas no âmbito do SEAF fossem minimizadas.

\section{FUNDO GARANTIDOR DA AGRICULTURA FAMILIAR}

Conforme estabelecido, este artigo propõe um mecanismo específico capaz de elevar a disponibilidade de recursos privados para o financiamento de pequenos empreendimentos agropecuários, de reduzir a dependência de fontes orçamentárias da União e de aprimorar o desempenho atuarial do SEAF. 
A disponibilidade de recursos para um empreendimento qualquer depende da capacidade do patrocinador convencer os financiadores de que o projeto é técnica e economicamente viável (ROSS et al., 2007). Sob o ponto de vista tecnológico, deve-se demonstrar que os processos são viáveis para a escala pretendida. Sob a ótica econômica, deve-se comprovar a capacidade do projeto em gerar um fluxo de caixa suficiente para cobrir o serviço da dívida do projeto, além de oferecer uma taxa de retorno adequada.

Contudo, independentemente do sucesso em se demonstrar a capacidade tecnológica e econômica dos projetos, uma escassez de recursos no mercado de crédito pode resultar dos problemas de seleção adversa e de risco moral, conforme demonstrado pela Teoria da Agência e apresentado na seção 2 desse artigo. Com efeito, o fundo garantidor pode compensar alguma parte do risco percebido pelos agentes financiadores ao não conseguir avaliar os estudos de viabiidade técnica e econômica e/ou monitorar a ação dos tomadores de recursos.

No caso de empreendimentos agrícolas incluídos no PRONAF, a escala de produção é pequena, a tecnologia empregada é relativamente defasada, o histórico de crédito é precário e as garantias oferecidas pelo produtor são notoriamente baixas. Esses fatores, entre outros, constam da própria justificativa para existência do Programa Federal e, notadamente, elevam o risco percebido por potenciais financiadores daquele tipo de produtor rural.

Como forma de contornar essas dificuldades, reduzir a dependência de recursos orçamentários e dirimir os efeitos do risco moral, propõe-se a criação de um fundo fiduciário garantidor composto por ativos integralizados pela União juntamente com contribuições de participantes dos programas acima relacionados. A criação de um fundo garantidor associado ao PRONAF advém da qualidade superior de um programa que mitigue adequadamente os riscos e que tenda a ser autossustentável.

A proposta envolve o levantamento de recursos financeiros para o financiamento de um projeto agrícola de pequeno porte economicamente separado de outros projetos, através da emissão de títulos (ou de empréstimos bancários), que têm por finalidade serem servidos e resgatados exclusivamente pelo fluxo de caixa do projeto, ou seja, com o uso da receita de comercialização da safra para 
saldar esses títulos. Em caso de inadimplência, o fundo garantidor deverá pagar o financiamento à primeira solicitação.

Considerando prazos adequados de vencimento da dívida e dos títulos patrimoniais, os títulos de dívida do projeto dependem, entre outros quesitos, da lucratividade e do valor das garantias apresentadas. No caso dos empreendimentos do PRONAF, um Fundo Garantidor de Crédito de Empreendimentos Agrícolas Familiares (FGSEAF) proveria garantias necessárias de tal forma que o risco de crédito dos parceiros privados fosse reduzido, assim como também seria reduzido o spread bancário para a obtenção dos financiamentos, na medida em que o fundo garantidor assegurasse a adimplência das obrigações financeiras do SEAF relativamente ao agricultor familiar. O risco que o FGSEAF deve assumir é o risco de crédito, ou seja, o risco de que as contraprestações não sejam pagas à instituição financeira financiadora de custeio da safra.

No caso da agricultura familiar, atividade econômica de pequena escala cuja estrutura de capital típica apresenta uma proporção de endividamento bastante elevada, o risco de crédito é grande e o acesso ao capital de terceiros somente ocorre a taxas de juros elevadas. Em tese, a proposta apresentada permite a alavancagem dos empreendimentos familiares através do aumento da capacidade de endividamento dos pequenos produtores a partir de fontes privadas de recursos. Isso pode ocorrer porque cada pequeno projeto agrícola constante do conjunto de projetos integrantes do PRONAF consiste em uma entidade independente, com atividade contábil separada dos demais projetos - um arranjo chamado de off-balance-sheet.

\subsection{PATRIMÔNIO DO FUNDO GARANTIDOR (FGSEAF)}

O patrimônio do FGSEAF deve ser formado pelo aporte de bens e direitos realizados pelos cotistas, por meio da integralização de cotas e pelos rendimentos obtidos com sua administração. A integralização das cotas deverá ser realizada através de dotações orçamentárias, títulos da dívida pública, ações de sociedade de economia mista etc. Tais fontes servirão de garantias aos investidores privados em projetos do PRONAF.

Além dessas fontes de recursos, e com o objetivo de aprimorar o resultado 
atuarial do fundo, o agricultor familiar pode ser chamado a contribuir, para a integralização do fundo, com uma parcela de sua receita em períodos de resultado positivo.

Considerando, por exemplo, o programa Compra Direta da Agricultura Familiar (CDAF), a contribuição do agricultor familiar pode se dar conforme o seguinte esquema: o agricultor habilitado poderá vender sua produção para o governo sempre que o preço de mercado no âmbito do produtor $\left(P_{M}\right)$ for inferior ao preço de referência estabelecido pelas autoridades públicas $\left(P_{R}\right)$, ou seja:

$$
P_{M}<P_{R}
$$

Para que o programa CDAF contribua para o Fundo Garantidor do Seguro da Agricultura Familiar, precisa ser modificado. Seja $\delta>0$ um parâmetro limitador do preço pago pelo governo ao agricultor familiar habilitado no programa CDAF, constituindo um parâmetro de política, tal que:

$$
\delta=\overline{\mathbb{C}}-P_{M}
$$

em que $\overline{\mathbb{C}}$ é o custo total médio estimado de produção do agricultor familiar, incluído o custo de amortização, e $P_{M}$ é preço de mercado no âmbito do produtor. Determinando $\delta>0$, a equação (2) garante que o agricultor familiar não terá prejuízo. Na presença desse parâmetro $\delta$, o recebimento líquido do agricultor será:

$$
\min \left\{P_{R}, P_{M}+\delta\right\}
$$

e a contribuição ao fundo garantidor ocorrerá somente em caso de resultado positivo, ou seja, caso o preço de mercado supere o preço de referência em montante superior a $\delta$. A contribuição ao fundo poderá ser fixada em um montante não superior ao excesso de $P_{R}$ sobre $P_{M}+\delta$. Dessa forma, como se queria demonstrar, a contribuição absoluta ao fundo será maior em estados da natureza mais favoráveis. 
Com efeito, os programas de compra antecipada contribuiriam para o Fundo Garantidor da Agricultura Familiar, sempre que o preço de vencimento da CPR, por unidade do produto comercializado, fosse maior do que o preço de mercado na época do vencimento, e o Governo realizaria depósito da diferença no FGSEAF. Alternativamente, pode-se adicionar outra fonte de recursos, tal como nos casos de venda da CPR no mercado secundário por valor superior ao valor recebido pelo agricultor, circunstância em que, ao serem descontados os custos de operação e spreads, a diferença seria depositada no FGSEAF.

Considerando-se o programa Contrato de Garantia de Compra da Agricultura Familiar (CGCAF), o agricultor participante contribuiria para o FGSEAF através de opção de compra com posição vendida. Neste caso, o agricultor compraria a opção, junto ao governo, com as seguintes características:

- O preço da opção é determinado por modelo do tipo Black-Scholes.

- O preço de exercício é $\mathrm{P}_{\mathrm{R}}$.

- O preço de exercício é estimado com base no mercado de futuros.

As equações do modelo Black-Scholes são (ROSS et al., 2007):

$$
\begin{aligned}
& C=S_{0} N\left(d_{1}\right)-X e^{-r t} N\left(d_{2}\right) \\
& d_{1}=\frac{\ln \left(\frac{S_{0}}{X}\right)+\left(r+\left(\frac{\sigma^{2}}{2}\right)\right) t}{\sigma \sqrt{t}} \\
& d_{2}=d_{1}-\sigma \sqrt{t}
\end{aligned}
$$

em que $C$ é o valor da opção de compra, $S_{0}$ é o preço spot ou corrente da ação (ativo-objeto), $N(z)$ representa a função normal cumulativa de uma variável normalmente padronizada, $X$ é o preço de exercício do ativo-objeto, $e$ é a base dos logaritmos naturais (2,718282), $r$ é a taxa de juros nominal contínua projetada até o vencimento da opção, $t$ é o tempo para o vencimento da opção e $\sigma=$ volatilidade do preço do ativo-objeto. 
Intuitivamente, o modelo assume que o valor da opção $\mathrm{C}$ é a diferença entre o valor presente do ativo (primeiro termo) e o valor presente do fluxo de pagamentos acordados no contrato (segundo termo). O modelo Black-Scholes estabelece, então, que esses dois valores derivam de uma distribuição de probabilidades $N($.$) , afinal$ constituem estimativas de realizações futuras de variáveis aleatórias, construídas a partir de dados observáveis.

A aplicação do modelo de Black-Scholes, no caso proposto, serve ao propósito de calcular o preço de referência de forma que, se superior ao preço de mercado $\left(P_{M}<P_{R}\right)$, o agricultor exerce a opção e vende sua produção para o governo, caso contrário o agricultor não exerce a opção. $O$ valor pago pela opção destina-se ao Fundo.

Diga-se que as expressões do modelo Black-Scholes determinam os preços de opções europeias de compra. A opção europeia pode ser exercida somente na data de vencimento (ROSS et al., 2007).

Resumindo, em ambos os exercícios feitos, o desempenho atuarial do SEAF será melhorado, pois o agricultor participante do CDAF ou do CGCAF reparte com o Governo (na figura do FGSEAF) os benefícios auferidos em épocas boas.

\subsection{IMPLEMENTAÇÃO DO FUNDO GARANTIDOR}

Quanto à implementação, o Fundo Garantidor deve ter natureza privada e patrimônio próprio separado do patrimônio dos cotistas. Sua regulamentação deve ser clara, bem como os termos para a qualificação e assinatura do termo de adesão. A integralização das cotas ainda dependerá da definição do estatuto e regulamento. Contudo, deve ficar claro que a participação da União como cotista deve ser limitada a um montante específico definido por Lei, bem como deve ser definido o limite de suas garantias, restrito a esse mesmo montante. Observe-se que a implementação do FGSEAF não implica em uma estrutura financeira totalmente inovadora no Brasil, bastando tomar-se como exemplo para sua constituição o que se passa com os Fundos Garantidores de Parcerias Público-Privadas, instituídos pela Lei $\mathrm{n}^{\mathrm{0}}$ 11.079, de 30 de dezembro de 2004.

Os recursos do FGSEAF devem ser depositados em conta especial 
junto à instituição financeira selecionada, cuja função consiste em zelar pela manutenção da rentabilidade e liquidez do Fundo Garantidor e responder judicial e extrajudicalmente. Cabe à Secretaria de Gestão do PRONAF deliberar sobre a gestão e alienação de bens e direitos do FGSEAF, bem como se manifestar sobre a utilização do Fundo para garantir o pagamento de obrigações pecuniárias assumidas pelos parceiros públicos.

O fundo deve ter natureza privada e estar sujeito aos direitos e obrigações próprios do Direito Privado (ALVARENGA, 2005), deixando de ser contingenciável e executável em regime de precatórios, o que reduz o risco de não cumprimento das obrigações pecuniárias contraídas pela Administração Pública. Isso torna mais atraente aos credores a alternativa do financiamento do custeio da safra de pequenos agricultores.

As obrigações pecuniárias contraídas pelos parceiros do PRONAF poderão ser garantidas por vinculação de receitas, instituição ou utilização de fundos especiais, contratação de seguro-garantia, garantia prestada por organismos internacionais ou instituições financeiras, garantias prestadas por fundo garantidor ou empresa estatal criada para esse fim, além de outros mecanismos admitidos em lei.

Diferentemente dos demais financiamentos, no financiamento da agricultura familiar, a atividade de um produtor é uma entidade jurídica distinta; os ativos do projeto, os contratos a ele relacionados e o fluxo de caixa do referido projeto são segregados da entidade patrocinadora em grau substancial. A estrutura de financiamento é projetada de forma a alocar retornos financeiros e riscos com maior eficiência que a da estrutura do financiamento convencional. Ademais, faz-se necessário que o projeto tenha uma vida finita - o que é o caso de uma única safra.

Para que um projeto obtenha financiamento como entidade econômica separada, os relacionamentos entre os participantes devem ser discriminados em contratos detalhados. Deve-se exigir que o projeto tenha fontes de suporte de crédito na forma de contratos de compra de produção do projeto e/ou de fornecimento dos insumos necessários a custos controlados. O contrato de compra, presente no CDAF, não dá garantia do pagamento da dívida de custeio - isso justifica o desenvolvimento de mecanismo capaz de gerar credibilidade creditícia.

A lógica que sustenta esse tipo de financiamento prevê um dimensionamento 
justo de risco e, portanto, requer garantias para que as projeções de resultados se confirmem. Isso implica em uma receita de venda do produto final garantida durante, pelo menos, o período de pagamento da dívida. É necessário, então, com poucas exceções, que se possa efetuar a venda de seus produtos finais através de contratos futuros.

\section{CONSIDERAÇÕES FINAIS}

Este artigo trata de programas governamentais de fomento à atividade agrícola de pequena escala, a agricultura familiar, e de geração de renda de pequenos produtores rurais. Em que pese o relativo sucesso dos programas dessa natureza no Brasil, tais como o Programa Nacional de Fortalecimento da Agricultura Familiar (PRONAF) e mecanismos associados de compra garantida e de seguro (SEAF), o artigo aponta dois aspectos que podem ser objeto de melhorias: (i) a dependência de recursos orçamentários oficiais e (ii) o desempenho atuarial.

A dependência de recursos orçamentários oficiais impõe limite ao crescimento do programa, cuja cobertura fica limitada à existência de recursos, a sua designação e ao seu não contingenciamento pelo governo federal. Dado o caráter meritório do apoio à agricultura familiar, tais restrições deveriam ser evitadas. Em relação ao desempenho atuarial do seguro associado ao PRONAF, aponta-se o seu déficit como outro aspecto inibidor do crescimento do Programa.

Como forma de contornar esses dois aspectos negativos, o artigo propõe a criação de um fundo fiduciário garantidor, composto por ativos integralizados pela União juntamente com contribuições compulsórias dos agricultores que acessam os programas governamentais. $\mathrm{O}$ fundo garantidor serviria ao propósito de assegurar o serviço de dívidas de agricultores contraídas junto a instituições financeiras privadas, em caso de perdas de produção. Ao prestar garantia de pagamento das obrigações pecuniárias assumidas pelos parceiros públicos em virtude do PRONAF, o fundo garantidor assumiria, portanto, o risco de crédito. Nos períodos de resultados positivos, os agricultores fariam aportes de recursos ao Fundo, de forma que o resultado atuarial do seguro da agricultura familiar fosse melhorado. 
A proposição aqui apresentada consiste, portanto, em uma forma alternativa para financiamento dos projetos do PRONAF, empreendimentos economicamente separáveis, o que dará origem a recursos a partir da comercialização dos produtos resultantes desses projetos. Tais recursos consistirão de fonte primária para atender ao serviço de seus empréstimos contraídos junto a investidores privados e fornecer o retorno sobre o investimento.

\section{REFERÊNCIAS}

ALVARENGA, J. E. Parcerias público-privadas: comentários à lei brasileira. São Paulo: Mapontes, 2005.

AZEVEDO, G. H. W. Seguros, matemática atuarial e financeira: uma abordagem introdutória. São Paulo: Saraiva, 2010.

AZÚA, D. R. Project finance: uma modalidade de financiamento internacional. São Paulo: Ed. Aduaneiras, 2002.

BAYE, M. R. Economia de empresas e estratégias de negócios. Porto Alegre: Bookman, 2010.

BCB - BANCO CENTRAL DO BRASIL. Relatório de gestão do exercício de 2012. Brasília, Março/2013.

BCB - BANCO CENTRAL DO BRASIL. Relatório de gestão do exercício de 2014. Brasília, Março/2014.

BODIE, Z.; KANE, A.; MARCUS, A. J. Investments. New York: McGraw-Hill/Irwin Series in Finance, Insurance and Real Estate, 2010.

BOQUI, F. Handbook of governmental accounting. New York: CRC Press, 2008.

BUAINAIN, A. M.; SOUZA FILHO, H. M. Política agrícola no Brasil: evolução e principais instrumentos. In: M. O. Batalha (Org.) Gestão agroindustrial 2. São Paulo: Atlas, 2001.

CARVALHO, C. de O.; SANTOS, A. C. dos; CARVALHO, G. R. Rede Brasil rural: inovação no contexto da agricultura familiar. Revista em Agronegócio e Meio Ambien- 
te, v. 8, n. 1, p. 79-94, jan./abr. 2015.

CHAMBERS, R. Insurability and Moral Hazard in Agricultural Insurance Markets. American Journal of Agricultural Economics, v. 71, n. 3, p. 604-616.

CHANCE, C. Project finance. London: IFR Publishing, 1991.

FREITAS, A. F. de; FREITAS, A. F.; DIAS, M. N. Mudanças conceituais do desenvolvimento rural e suas influências nas políticas públicas. Revista de Administração Pública, v. 46, n. 6, p. 1575-97, nov./dez. 2012.

GARDNER, B. Crop insurance in U. S. farm policy. In: HUETH, D. L.; FURTAN, W. H. (Ed.) Economics of agricultural crop insurance: theory and evidence. Boston: Kluwer Academic Publishers, 1994.

GUANZIROLI, C. E. PRONAF dez anos depois: resultados e perspectivas para o desenvolvimento rural. Revista de Economia e Sociologia Rural, v. 45, n. 2, p. 301328, abr.jun. 2007.

GUILHOTO, J. J. M.; SILVEIRA, F. G.; ICHIHARA, S. M.; AZZONI, C. R. A importância do agronegócio familiar no Brasil. Revista de Economia e Sociologia Rural, v. 44, n. 3, p. 355-382, jul./set. 2006.

GUSE, J. C.; POLITELO, L.; LEITE, M.; SILA, T. P. da. Propriedade familiar e desempenho de empresas do agronegócio brasileiro. Revista em Agronegócio e Meio Ambiente, v. 8, n. 2, p. 271-289, maio/ago. 2015.

MACHADO, M. R. C.; PAULO, E. Seguros. In: I. S. Lima; G. A. S. F. Lima; R. C. Pimentel. Curso de mercado financeiro: tópicos especiais. São Paulo: Atlas, 2006.

MENDES, J. T. G.; PADILHA JUNIOR, J. B. Agronegócio: uma abordagem econômica. São Paulo: Pearson Prentice Hall, 2007.

MILGROM, P.; ROBERTS, J. Economics, organization and management. Prentice Hall, 1992.

OZAKI, V. A.; SHIROTA, R. A. Experiência do seguro agrícola nos EUA: evolução e performance. Revista Brasileira de Risco e Seguro, v. 1, n. 2, p. 69-87, out./mar. 2006.

QUIGGIN, J.; KARAGIANNIS, G.; STANTON, J. Crop insurance and crop production: an empirical study of moral hazard and adverse selection. Australian Journal of 
Agricultural Economics, v. 7, n. 2, p. 95-113, August 1993. ROSS, S. A.; WESTERFIELD, R. W.; JAFFE, J. F. Administração financeira: Corporate Finance. São Paulo: Atlas, 2007.

SANGALLI, A. R.; SILVA, H. C. H.; SILVA, I. F.; SCHLINDWEIN, M. M. Associativismo na agricultura familiar: contribuições para o estudo do desenvolvimento no assentamento rural Lagoa Grande, em Dourados (MS), Brasil. Organizações Rurais \& Agroindustriais, v. 17, n. 2, p. 225-238, 2015.

SERENINI, M. J.; MALYSZ, S. T. A importância da agricultura familiar na produção de alimentos. Curitiba: Cadernos PDE, 2015.

SILVA, A. Contabilidade e análise econômico financeira de seguradoras. São Paulo: Atlas, 1999.

SKEES, J. R. Agricultural risk management or income enhancement? Regulation, v. 22, n. 1, p. 35-43, Spring 1999.

Recebido em: 17/02/2016

Aceito em: 24/05/2018 